\title{
A INFLUÊNCIA DAS AÇÕES COLETIVAS EM PROCESSOS DE APRENDIZAGEM: ESTUDO DE CASO EM UM APL DE ARTESANATO E CERÂMICA
}

\section{THE INFLUENCE OF COLLECTIVE ACTIONS IN LEARNING PROCESSES: A CASE STUDY IN AN APL OF CRAFTS AND CERAMICS}

\author{
Wenceslau Almada Pessoa Neto \\ Faculdade de Ensino Superior do Piauí \\ Fortaleza, CE, Brasil \\ E-mail: wapn14@gmail.com
}

Fátima Regina Ney Matos

Coordenadora e Professora do Programa de Pós-Graduação em Administração da Universidade de Fortaleza - UNIFOR

Fortaleza, CE, Brasil

E-mail: fneymatos@unifor.br

\section{Diego de Queiroz Machado}

Doutorando do Programa de Pós-Graduação em Administração da Universidade de Fortaleza - UNIFOR

Fortaleza, CE, Brasil

E-mail: diegoqueirozm@yahoo.com.br

Maria Clara Cavalcante Bugarim

Diretora do Centro de Ciências da Comunicação e Gestão e Professora do Programa de Pós-Graduação em Administração da Universidade de Fortaleza - UNIFOR

Fortaleza, CE, Brasil

E-mail: diegoqueirozm@yahoo.com.br

\section{Augusto Marcos de Carvalho Sena}

Professor do Programa de Pós-Graduação em Administração da Universidade de Fortaleza - UNIFOR

Fortaleza, CE, Brasil

E-mail: amsena@unifor.br

\section{RESUMO}

Esta pesquisa tem como objetivo analisar as principais ações coletivas existentes em um Arranjo Produtivo Local (APL), identificando as suas influências na aprendizagem de seus agentes. Portanto, como uma das manifestações empíricas do empreendedorismo coletivo, o APL Arte Cerâmica Vermelha, situado em Teresina, no Piauí, foi o objeto de estudo deste trabalho. Para a coleta de dados, foram utilizadas fontes primárias e secundárias de dados, sendo elas: documentos, registros em arquivos, observações diretas e aplicação de entrevistas estruturadas e semiestruturadas com os agentes integrantes do APL. Em relação às ações coletivas mapeadas, algumas se mostraram tão relevantes para o APL que serviram de base para o surgimento de novas ações, tendo o caráter de associativismo e de qualificações. Com isso, foi possível concluir que tais processos de aprendizagem aconteceram por intermédio da aprendizagem sócio prática, levando-se em consideração as práticas de cooperação e de interação presentes no arranjo.

Palavras-chave: Ações coletivas. Processos de aprendizagem. Arranjos produtivos locais.

Empreendedorismo coletivo. Estudo de caso.

\section{ABSTRACT}

This research aims to analyze the main collective actions existing in a cluster, identifying their influences on the learning of his agents. Therefore, as one of the empirical manifestations of collective entrepreneurship, the cluster Arte Cerâmica Velha, located in Teresina, Piauí, was the object of study of this work. For data collection, primary and secondary sources of data were used, such as: documents, records in files, direct observations and application of structured and semi-structured interviews with cluster's agents. Regarding collective action mapped, some proved as relevant to cluster which formed the basis for the emergence of new shares, having the character of associations and qualifications. Thus, it was concluded that such learning processes occurred through social-learning practice, taking into account the practices of cooperation and interaction in the present arrangement.

Keywords: Collective actions; Learning processes; Clusters; Collective entrepreneurship; Case study. 


\section{INTRODUÇÃO}

Questões como o empreendedorismo, ações coletivas e redes sociais são hoje bastante discutidas no mundo acadêmico e têm chamado para si o interesse internacional, nacional e local. O empreendedorismo coletivo tem como uma de suas principais características a dependência de variáveis como: laços de rede, interdependência, contexto social, origens locais, a dinâmica da comunidade e oportunidades conjuntas (BURRESS; COOK, 2009). Por meio dessas, outras características podem ser mencionadas, como a territorialidade, a competitividade e a cooperação para que as ações entre empresas e outros atores interessados aconteçam.

Portanto, considera-se que o empreendedorismo coletivo pode ser mais bem observado em aglomerações produtivas, uma vez que nelas estão presentes a maioria dessas variáveis que o caracterizam (JOHANNISSON, 1998). Dentre tais aglomerações, destacam-se, para os fins dessa pesquisa, os Arranjos Produtivos Locais (APLs), a sua rede de relações, as ações coletivas decorrentes das interações e o seu, consequente, aprendizado. Já que "as relações sociais existentes em APLs são capazes de facilitar a coordenação e o envolvimento dos agentes em ações cooperativas que levem a um desempenho econômico superior" (MONTEIRO; REGIS; MELO, 2010, p. 50).

Acredita-se que as empresas pertencentes a um APL possuem grande potencial de aprendizagem em virtude das ações coletivas decorrentes de sua rede de relações, pois se percebe a existência de uma busca contínua para a evolução dos seus processos, cuja finalidade é aumentar, sobretudo, a sua capacidade produtiva e inovativa, agregando impactos socioeconômicos nas comunidades nas quais estão inseridas. Tal aprendizagem, por sua vez, pode ser considerada o meio pelo qual as organizações adquirem e elevam o seu conhecimento, desenvolvendo e aprimorando os seus processos para melhor interagirem com os seus meios internos e externos, operando de maneira inteligente e autorreguladora (ARGYRIS; SCHÖN, 1978; MORGAN, 1996; PETERS, 1998; SENGE, 1990).

Diante dessa perspectiva, esta pesquisa tem como objetivo geral analisar as principais ações coletivas existentes em um APL, identificando as suas influências na aprendizagem de seus agentes. Portanto, como uma das manifestações empíricas do empreendedorismo coletivo, o APL Arte Cerâmica Vermelha, situado em Teresina, no Piauí, foi o objeto de estudo deste trabalho. Segundo levantamento divulgado pelo MIDIC (BRASIL, 2008), por meio do Grupo de Trabalho Permanente (GTP) para APLs, o Arranjo Produtivo Local Arte Cerâmica Vermelha, formado por 23 lojas, é responsável pela geração de uma grande quantidade empregos formais e informais. Para a região onde está localizado, o incentivo da atividade do artesanato da cerâmica vermelha tornou-se estratégico, mesmo pelo fato de ser uma das únicas alternativas de desenvolvimento para a população.

No entanto, convém destacar que esta pesquisa se limitou a buscar entender como se dão as formas de aprendizagem a partir das ações coletivas promovidas pela rede social do empreendimento coletivo mencionado e, não, descrever as diversas etapas e estágios do aprendizado dos artesãos desde a origem até os dias atuais.

Vale lembrar que os APLs, em sua maioria, são constituídos por micro, pequenas e médias empresas (MPMEs) e, em boa parte dos países desenvolvidos e em desenvolvimento, entre estes, o Brasil, essas empresas e suas relações têm expressiva participação no desempenho das economias nacionais. No caso 
brasileiro, segundo o Boletim Estatístico de Micro e Pequenas Empresas (SEBRAE, 2005), as MPMEs representam $98 \%$ do total de empresas brasileiras, $60 \%$ da força de trabalho, $48 \%$ da produção nacional e $42 \%$ dos salários. Assim, a simples constatação desses dados é suficiente para ratificar a importância dessas empresas na economia do país. E uma maneira adequada de desenvolvê-las seria por meio de APLs, dandoIhes maior dinamismo em pesquisa e desenvolvimento tecnológico, como atestam os casos dos Distritos Industriais da Terceira Itália, do Vale do Silício na Califórnia e do Vale dos Sinos no Rio Grande do Sul (LASTRES et al., 2002).

Convém, ainda, enfatizar que a relevância de tal pesquisa acopla-se perfeitamente às aspirações governamentais, tanto em âmbito federal quanto estadual, no sentido de fomentar a produção do conhecimento científico-tecnológico em busca da geração de riquezas e da melhoria na qualidade de vida, gerando empregos, diminuindo as desigualdades econômicas e sociais com vistas a promover o desenvolvimento econômico e social, sobretudo em uma região onde existem tantas contradições econômicosociais.

\section{APRENDIZAGEM EM ARRANJOS PRODUTIVOS LOCAIS}

A compreensão da aprendizagem em APLs necessita, inicialmente, da visão econômica tanto do conhecimento quanto do aprendizado das firmas. Nesse tipo de visão, "o conhecimento constitui hoje um importante fator de competitividade, podendo ser avaliado tanto como insumo (competência) como um produto (inovação) no processo produtivo; ou seja, reflete-se em competências necessárias para inovar e ser flexível a mudanças" (MACIEL; ALBAGLI, 2002, p. 7). Já o "aprendizado [...] está associado a um processo cumulativo por meio do qual as firmas ampliam seus conhecimentos, aperfeiçoam seus procedimentos de busca e refinam suas habilidades em desenvolver, produzir e comercializar bens e serviços" (LASTRES; CASSIOLATO, 2003, p. 9).

Para Lastres e Cassiolato (2003), corroborando o pensamento de Peters (1998), a aprendizagem é um processo cumulativo de experiências que se transformam em conhecimento tácito e codificado em prol do desenvolvimento das empresas. Além disso, segundo os mesmos autores, a aprendizagem é a grande responsável pelo aumento da capacidade produtiva e inovativa das empresas e instituições de um APL.

$\mathrm{Na}$ abordagem de Maciel e Albagli (2002, p. 7), a aprendizagem em APLs "refere-se à aquisição e à construção de diferentes tipos de conhecimentos, competências e habilidades, não se limitando a ter acesso a informações", como pode acontecer na socialização de conhecimentos codificados. Para tanto, os autores destacam a necessidade de identificação das diferentes formas de aprendizado em APL, tais como: learningby-doing, learning-by-using, learning-by-searching, learning-by-imitating, learning-by-interacting e learningby-cooperating.

De acordo com Arrow (1962), o aprendizado é oriundo da experiência (learning-by-doing) e esse aprendizado tem implicações na economia das firmas. O learning-by-doing acontece por meio dos investimentos que a empresa aporta no seu processo produtivo. No entendimento do referido autor, o investimento é responsável pela geração de novos processos e produtos que devem ser assimilados e aprendidos pelos profissionais com a experiência que vão adquirir, aumentando o repositório de conhecimento da firma. 
Por sua vez, para Rosenberg (1982), o learning-by-using é a aprendizagem que ocorre via o uso do produto, realizada de forma consciente e promovendo melhorias nos processos de produção e uso. Por exemplo, o produtor de bens de capital aprende com a experiência dos usuários de seus produtos (MUKOYAMA, 2006). Assim, o desempenho de um produto está condicionado à aprendizagem decorrente do seu uso, devido o longo período de experimentações a que ele é submetido e das características surgidas após a sua utilização intensa e prolongada (ROSENBERG, 1982).

Já o learning-by-searching, para Malerba (1992), é o aprendizado por pesquisa ou busca. Ele está vinculado às atividades cuja finalidade é a criação de novos conhecimentos, responsáveis pela inserção de inovações incrementais e radicais. Ainda na visão de Malerba (1992), o aprendizado por pesquisa ou busca contribui para a diferenciação vertical de produto, com base nos processos de pesquisa e desenvolvimento de novos produtos de qualidade e desempenho comprovados.

O aprendizado por imitação (learning-by-imitating) foi inicialmente analisado por Bandura (1962) quando identificou que a observação e a imitação feitas pelo indivíduo aceleram o processo de aprendizagem. De forma similar, nas organizações, a aprendizagem por imitação acontece quando a firma reproduz inovações de outras empresas, muitas vezes utilizando métodos poucos rigorosos e até mesmo ilegais de apropriação do conhecimento. Embora, nem sempre tão perceptível, para Cassiolato (2004), esse tipo de aprendizagem é muito mais utilizado pelas firmas do que se imagina. Além disso, a aprendizagem por imitação "necessita da existência de ampla capacitação interna para se realizar engenharia reversa, estando associada à: mobilidade de trabalho e troca formal e informal de informações" (CASSIOLATO, 2004, p. 6).

O learning-by-interacting, com base nos estudos de Lundvall (1988), é uma das principais formas de aprendizagem para as firmas. A aprendizagem ocorre por meio do relacionamento entre usuários e fornecedores ao longo da cadeia de produção, gerando um grande potencial inovador. Assim, o entendimento da dinâmica dessa forma de aprendizado "está relacionada às possibilidades de transferência de informações e conhecimentos, e as especificidades da dinâmica da inovação" (CAMPOS et al., 2003, p. 53).

Por fim, o learning-by-cooperating é oriundo da colaboração com outras firmas, competidores, instituições de pesquisa e de capacitação, entre outras organizações (CASSIOLATO, 2004). Para Bureth, Wolff e Zanfei (1997) o aprendizado por cooperação exige compromisso das firmas, pois elas mobilizaram recursos, que poderão ser perdidos em caso de quebra da aliança por alguma das empresas aliadas. Segundo os autores, isso pode ocorrer devido a dois fatores:

Em primeiro lugar, o compromisso ajuda a reduzir a variedade e a variabilidade dos contextos em que a cooperação ocorre, criando assim "janelas estáveis" dentro do qual os agentes podem aprender. Em segundo lugar, as empresas precisam investir de forma irreversível em habilidades de comunicação, procedimentos e facilidades, a fim de absorver e utilizar os bens trocados e compartilhados com os parceiros. (BURETH; WOLFF; ZANFEI, 1997, p. 4).

Dessa forma, a aprendizagem em APL surge com a combinação de diversas formas (CAMPOS et al., 2003; LASTRES; CASSIOLATO, 2003; MACIEL; ALBAGLI, 2002). Uma delas leva em consideração o ambiente interno e o ambiente externo no qual estão inseridas as empresas. De acordo com Malerba (1992), como forma de aprendizagem interna, podem ser elencados o aprendizado por experiência (learning-bydoing), o aprendizado por uso (learning-by-using) e o aprendizado por pesquisa ou busca (learning-bysearching). Desse modo, o aprendizado a partir de fontes internas da firma está relacionado ao "aprendizado 
com experiência própria, no processo de produção, comercialização e uso, na busca de novas soluções técnicas nas unidades de pesquisa e desenvolvimento" (LASTRES; CASSIOLATO, 2003, p. 9).

Quanto às formas de aprendizagem externa, Malerba (1992) destaca o aprendizado por imitação (learning-by-imitating), o aprendizado por interação (learning-by-interacting) e o aprendizado por cooperação (learning-by-cooperating). Assim, o aprendizado a partir de fontes externas se dá por meio da "interação com fornecedores, concorrentes, clientes, usuários, consultores, sócios, universidades, instituição de pesquisa, prestadores de serviços tecnológicos, agências e laboratórios governamentais, organismos de apoio, entre outros" (LASTRES; CASSIOLATO, 2003, p. 9).

Essa combinação proposta por Malerba (1992) é a mais adequada quando se trata de aprendizagem em APLs (CAMPOS et al., 2003; LASTRES; CASSIOLATO, 2003; MACIEL; ALBAGLI, 2002). Afinal, quanto maiores e mais diversificadas forem as formas e fontes de aprendizado, maior será o acúmulo de conhecimentos por parte das firmas. A identificação destas fontes é fundamental para que se possa compreender as formas e como ocorre o processo de aprendizado das organizações em um APL específico.

\section{MÉTODO DE PESQUISA}

Considerando-se que a escolha do método e, por consequência, da abordagem de uma pesquisa deve ser em função do fenômeno que se pretende estudar (SILVERMAN, 2009), neste estudo foi utilizada a abordagem qualitativa dada à subjetividade, complexidade e necessidade de observação do fenômeno (MINAYO, 2007). Dentre os métodos qualitativos propostos por Merriam (1998), foi empregado o estudo de caso, cuja opção, segundo Godoy (1995), justifica-se por considerá-lo o tipo mais adequado para a resolução da problemática levantada, na qual houve a necessidade de uma forte proximidade com o contexto e a realidade em que as empresas do APL estudado estão inseridas. Tal compreensão favorece a geração de hipóteses e pressupostos que podem ser replicados e testados em outros contextos similares para uma maior generalização, como defende Yin (2005).

$\mathrm{Na}$ coleta de dados foram utilizadas fontes primárias e secundárias sobre o APL Arte Cerâmica Vermelha e a aprendizagem organizacional, por meio de documentos, registros em arquivos, observações diretas e aplicação de entrevistas estruturadas e semiestruturadas, previamente testadas, no campo de pesquisa. A utilização dessa diversidade de instrumentos de obtenção de evidências empíricas deve-se a complementaridade que os mesmos propiciam (YIN, 2005), já que, conforme Alves-Mazzotti (2006, p. 648), "os estudos de caso não são fáceis de serem realizados, ao contrário, eles se revestem de grande complexidade, o que exige o recurso a técnicas variadas de coleta de dados"

Dessa forma, a pesquisa documental e os registros em arquivos tiveram como intento coletar, catalogar e mapear empresas e informações pertinentes à compreensão do APL Arte Cerâmica Vermelha em Teresina, por meio de livros, jornais, revistas, bancos de dados, periódicos, internet, entre outras fontes de dados. Por sua vez, as observações diretas ocorreram concomitantemente à aplicação dos questionários e das entrevistas, pois a pesquisa de campo ao local escolhido é considerada como um momento oportuno para fazer essas observações (YIN, 2005). 
O questionário foi elaborado com perguntas fechadas e aplicado por contato direto entre o pesquisador e o respondente. Ele teve como função identificar todos os agentes, internos e externos, que se relacionam com o APL. Para tanto, a técnica utilizada foi o cartão gerador de nomes (RÉGIS, 2005). Os respondentes citaram os nomes dos agentes que consideravam mais importantes dentro e fora do APL. Nessa etapa da pesquisa, foram considerados como respondentes os artesãos, familiares, empregados, fornecedores, clientes e demais representantes de organizações cujos nomes foram citados como importantes instituições que atuam no APL na medida em que tal processo se efetivava. Nessa fase, foram aplicados 120 questionários com os sujeitos acima indicados, à medida que eram citados no cartão gerador de nomes. Buscando-se uma maior confiabilidade e validade para este estudo, optou-se por aplicar os questionários em todas as 23 lojas do polo, bem como em todas as instituições onde se encontravam os sujeitos de pesquisa mencionados nos cartões, no período de outubro a novembro de 2012. Ao todo, foram apontados nos questionários 120 diferentes agentes.

Em seguida, foi aplicada a entrevista semiestruturada com os agentes considerados mais influentes para o APL, considerando, neste caso, como os mais influentes, aqueles foram mais citados nos cartões gerados de nomes. Buscou-se com esse instrumento, identificar as principais ações coletivas, suas propriedades e suas influências na aprendizagem do APL. Assim, as entrevistas tornaram-se os principais instrumentos de coleta de dados para o alcance do objetivo proposto, sendo realizadas 11 entrevistas gravadas por meio digital, no período de dezembro de 2012 a janeiro de 2013. Para garantir a autenticidade da pesquisa, utilizou-se o princípio da redundância ou saturação. "As informações acumuladas por meio da saturação promovem a fidedignidade, que ocorre quando as opiniões dos entrevistados se tornam comuns, sem o acréscimo de informações novas" (MATOS, 2008, p. 81-82). Assim, a saturação foi percebida na $9^{a}$ entrevista, mas decidiu-se continuar até que todos os agentes previamente identificados participassem do processo, de modo a proceder com o tratamento e análise dos dados aqui obtidos.

Como suporte à análise dos dados, foi utilizado os softwares Microsoft Excel (versão 2012) e ATLAS.ti (versão 7.0). Os dados oriundos do questionário e obtidos pelo cartão gerador de nomes foram organizados, inicialmente, no Excel por meio da digitação, classificação e codificação. A relação de agentes identificados consta nos Quadros 1, 2 e 3, que seguem. 
Quadro 1 - Identificação dos agentes internos do APL Arte Cerâmica Vermelha

\begin{tabular}{|l|l|}
\hline REDE INTERNA & \\
\hline Loja A & Artesão: A1; Familiares: F1, F2 \\
\hline Loja B & Artesãos: A2, A3 e A4 \\
\hline Loja C & Artesãos: A5 e A6; Familiares: F3, F4 e F5 \\
\hline Loja D & Artesão: A7; Familiar: F6, Empregado: E1 \\
\hline Loja E & Artesãos: A8; A9; Familiares: F7 e F8 \\
\hline Loja F & Artesãos: A10 e A11; Familiares: F9 e F10; Empregado: E2 \\
\hline Loja G & Artesão: A12; Familiar: F11 \\
\hline Loja H & Artesãos: A13 e A14; Familiares: F12, F13 e F14 \\
\hline Loja I & Artesão: A15; Familiares: F15, F16 e F17 \\
\hline Loja J & Artesão: A16 e Familiar: F18 \\
\hline Loja L & Artesãos: A17 e Empregado: E3 \\
\hline Loja M & Artesãos: A18; Familiares: F19, F20, F21 e F22 \\
\hline Loja N & Artesãos: A19, A20 e A21; Familiares: F23, F24 e F25, Empregado: E4 \\
\hline Loja O & Artesãos: A22; Familiares: F26, F27 e F28 \\
\hline Loja P & Artesãos: A23 e A24; Familiares: F29, F30, F31, F32 e F33, Empregado: E5 \\
\hline Loja Q & Artesãos: A25 e Familiar: F34 \\
\hline Loja R & Artesãos: A26 e 27; Familiares: F35e F36 \\
\hline Loja S & Artesãos: A28 e A29; Familiares: F37, F38, F39 e F40 \\
\hline Loja T & Artesãos: A30, A31, A32, A33, A34, A35, A36, A37, A38, A39, A40, A41; Familiares: F41, F2, \\
\hline Loja U & F43, F44, F45 \\
\hline Loja V & Artesãos: A42; Familiar: F46 \\
\hline Loja X & Artesãos: A43 e A44; Familiares: F47, F48 e F49 \\
\hline Loja Z & Artesãos: A45; Familiares: F50 e F51 \\
\hline Nota: Para & Artesãos: A46; Familiar: F52; Empregado: E6 \\
\hline
\end{tabular}

Nota: Para efeitos desta pesquisa, artesãos são aqueles que trabalham diretamente com o manuseio do barro para fazer a cerâmica, familiares são parentes de primeiro ou segundo grau que exercem outras atividades na loja, e empregados são funcionários que exercem também atividades distintas do artesanato, mas não são parentes dos donos da loja.

Fonte: Dados da pesquisa.

\section{Quadro 2 - Identificação dos agentes externos do APL Arte Cerâmica Vermelha}

\begin{tabular}{|l|l|}
\hline REDE EXTERNA & \multicolumn{1}{|c|}{ AGENTES E CÓDIGOS } \\
\hline Clientes & CLT 1, CLT 2 e CLT 3 \\
\hline Fornecedores & FND1, FND2, FND3 E FND4 \\
\hline Fundação Banco do Brasil & FBB \\
\hline Fundação Wall Ferraz & FWF \\
\hline Governo do Estado do Piauí & GEP \\
\hline Instituto Federal de Educação, Ciência e Tecnologia do Piauí & IFIPI \\
\hline Instituto Walmart & IW \\
\hline Prefeitura Municipal de Teresina & PMT \\
\hline Secretaria Municipal de Desenvolvimento Econômico & SEMDEC \\
\hline Serviço Brasileiro de Apoio às Micro e Pequenas Empresas & SEBRAE/PI \\
\hline Serviço Nacional de Aprendizagem Industrial & SENAI \\
\hline
\end{tabular}

Fonte: Dados da pesquisa. 
Quadro 3 - Quantidade de agentes internos e externos do APL Arte Cerâmica Vermelha

\begin{tabular}{|c|c|}
\hline TIPOS DE AGENTES INTERNOS & QUANTIDADE \\
\hline Artesãos & 46 \\
\hline Familiares & 52 \\
\hline Empregados & 6 \\
\hline Total de Agentes Internos & 104 \\
\hline TIPOS DE AGENTES EXTERNOS & Q QUANTIDADE \\
\hline Clientes & 3 \\
\hline Fornecedores & 4 \\
\hline Fundação Banco do Brasil & 1 \\
\hline Fundação Wall Ferraz & 1 \\
\hline Governo do Estado Do Piauí & 1 \\
\hline Instituto Federal de Educação, Ciência e Tecnologia do Piauí - IFPI & 1 \\
\hline Instituto Walmart & 1 \\
\hline Prefeitura Municipal de Teresina & 1 \\
\hline Secretaria Municipal de Desenvolvimento Econômico - SEMDEC & 1 \\
\hline Serviço Brasileiro de Apoio às Micro e Pequenas Empresas - SEBRAE & 1 \\
\hline Serviço Nacional de Aprendizagem Industrial - SENAI & 1 \\
\hline Total de Agentes Externos & 16 \\
\hline TOTAL DE AGENTES MAPEADOS & 120 \\
\hline
\end{tabular}

Fonte: Dados da pesquisa.

Posteriormente, os dados obtidos pela entrevista semiestruturada foram transcritos, bem como foram ordenados os dados provenientes das observações e dos documentos. Esses dados, em específico, contribuíram para a identificação das principais ações coletivas originárias da rede de relações do arranjo. Além disso, eles foram codificados e submetidos à análise de conteúdo com a ajuda do ATLAS.ti. No entanto, antes de se proceder a análise de conteúdo, foi necessário definir o tipo de grade, as unidades e as categorias para análise. Assim, a grade escolhida foi do tipo mista (fechada e aberta), pois já existia uma categoria pertinente ao objeto de análise, sendo ela as ações coletivas no arranjo estudado. Entretanto, admitiu-se o surgimento e a inserção de novas categorias durante o processo de análise, como, por exemplo, o surgimento das subcategorias: associativismo e qualificação. Por meio delas, sugiram também, como "elementos integrantes" (VERGARA, 2010, p.7) do processo de análise: a liderança, a produção, a gestão e a comercialização. Como unidade de análise, foram definidos as frases e os parágrafos. E com base na grade de análise escolhida, foram estabelecidas as categorias de análise, como mostra o Quadro 4, a seguir.

Quadro 4 - Grade mista de análise

\begin{tabular}{|c|l|l|}
\hline \multicolumn{1}{|c|}{ Categoria } & \multicolumn{1}{|c|}{ Subcategorias } & \multicolumn{1}{c|}{ Elementos Integrantes } \\
\hline \multirow{3}{*}{ Ações Coletivas } & Associativismo & Liderança \\
\cline { 2 - 3 } & \multirow{3}{*}{ Qualificação } & Produção \\
\cline { 3 - 3 } & & Gestão \\
\cline { 3 - 3 } & & Comercialização \\
\hline
\end{tabular}

Fonte: Dados da pesquisa.

Além disso, confrontou-se "os resultados obtidos com as teorias que [deram] suporte à investigação" (VERGARA, 2010, p.10), em busca de compreender como as ações coletivas influenciam nos processos de aprendizagem no APL Arte Cerâmica Vermelha de Teresina, no Piauí. 


\section{LÓCUS DA PESQUISA: APL ARTE CERÂMICA VERMELHA DE TERESINA}

A capital do Estado do Piauí, Teresina, foi fundada em 1852, às margens do Rio Poti. Sua origem, portanto, está ligada a este rio, onde se encontrava apenas uma vila de pescadores e de comerciantes. Posteriormente, outra atividade econômica foi desenvolvida com a descoberta das jazidas de argila na região, a fabricação de tijolos. As olarias, daí originadas, foram uma das principais fontes de geração de emprego e renda para a população, na referida vila que ficou conhecida como Poti Velho (TERESINA, 2003).

A descoberta dessa potencialidade endógena contribuiu para o desenvolvimento do principal polo cerâmico do Piauí, dando especial destaque para a produção de telhas, sendo considerada uma das melhores do Brasil (PIAUÍ, 2005). Contudo, o que era para ser motivo para o desenvolvimento, configurou-se no principal fator de declínio das olarias artesanais localizadas do Poti Velho, uma vez que não suportaram a concorrência com o polo cerâmico, composto por organizações industrializadas.

Porém, em função dos laços históricos e culturais do bairro Poti Velho, uma nova pontencialidade foi gerada, o turismo, que atuou como o agente catalizador do desenvolvimento local, trazendo políticas públicas com o fim de fomentar o desenvolvimento da atividade artesanal da cerâmica. Além disso, o fator ambiental contribuiu, também, para o desenvolvimento dessa atividade, uma vez que na região ocorre o encontro dos rios Poti e Parnaíba que rodeiam a cidade de Teresina, considerado como um fenômeno de beleza cênica (SILVA, 2011).

O turismo fez surgir um arranjo de artesãos que produziam peças cerâmicas de utlidades variadas e de decoração, com bastante aceitação pelos turistas que passaram a frequentar a região. "A arte, o artesanato, o artesão, a cerâmica e o turismo passaram a ser o referencial do bairro Poti Velho" (SILVA, 2011, p. 3). Contudo, não havia estrutura para produção, armazenagem e comercialização das peças. Com a carência de um espaço físico para a produção e para melhor atender os turistas que passaram a frequentar o local, surgiu o Polo Cerâmico Artesanal do Poti Velho, que foi inaugurado no dia 12 de outubro de 2006. Houve a construção de 23 lojas, que passaram a abrigar em média duas famílias. O espaço foi destinado à produção e à comercialização das peças cerâmicas produzidas pelos artesãos. Os produtos fabricados e comercializados são hoje apresentados em um portfólio com finalidades e opções diversas. São classificados, portanto, nas linhas utilitárias, decorativas, jardinagem, artes santeiras e bijuteria (LIMA, 2011).

Antes, porém, outra carência já havia sido detectada, a falta de organização e cooperação dos artesãos. Assim, primeiramente, os artesãos reuniram-se para a formação da Associação dos Ceramistas do Poti Velho (ACEPOTI) e, posteriormente, criaram a Cooperativa de Artesanato do Poti Velho (COOPERART POTI). Logo após a criação das duas instituições, o polo foi caracterizado como um aglomerado produtivo, passando a ser denominado de Arranjo Produtivo Local Arte Cerâmica Vermelha de Teresina pelo Ministério do Desenvolvimento, Indústria e Comércio Exterior - MIDIC (BRASIL, 2008). 


\section{APRESENTAÇÃO E ANÁLISE dOS RESULTADOS}

Inicialmente, com o intuito de mapear as principais ações coletivas do APL Arte Cerâmica Vermelha, bem como descrever como tais ações se convertem em formas de aprendizagem, foram identificadas várias ações coletivas, descritas pelos entrevistados na última fase de coleta de dados, mediante entrevista semiestruturada. O Quadro 5 apresenta essas ações, em ordem cronológica e de relevância para os entrevistados.

\section{Quadro 5 - Mapeamento das principais ações coletivas do APL Arte Cerâmica Vermelha}

\begin{tabular}{|l|l|l|}
\hline Ordem & Ação Coletiva & Atores Envolvidos \\
\hline 1 & Curso de associativismo & Artesãos e SEBRAE/PI \\
\hline 2 & $\begin{array}{l}\text { Veliação da Associação dos Artesãos em Cerâmica do Poti } \\
\text { VelhoTI) }\end{array}$ & Artesãos e SEBRAE/PI \\
\hline 3 & Criação do Polo Cerâmico Artesanal do Poti Velho & ACEPOTI, PMT e GEP \\
\hline 4 & Curso de produção de bijuteria em cerâmica & ACEPOTI e SEBRAE/PI \\
\hline 5 & $\begin{array}{l}\text { Criação da Cooperativa de Artesanato do Poti Velho } \\
\text { COOPERART) }\end{array}$ & Artesãos e SEBRAE/PI \\
\hline 6 & Projeto Casa Piauí Design & SEBRAE/PI, ACEPOTI e COOPERART \\
\hline 7 & Curso de especialização em cerâmica & ACEPOTI e SEBRAE/PI \\
\hline 8 & Estação Digital & FBB, ACEPOTI e COOPERART \\
\hline 9 & Núcleo de Qualificação Profissional & FWF, SENAI, SEBRAE/PI e CEFET \\
\hline 10 & Semana de Moda de Teresina & FWF e COPERART \\
\hline 11 & Capacitação em Gestão e em Design & $\begin{array}{l}\text { SEMDEC, SEBRAE/PI, ACEPOTI e } \\
\text { COOPERART }\end{array}$ \\
\hline 12 & I Feira de Artesanato do Polo Cerâmico Artesanal do Poti Velho & $\begin{array}{l}\text { PMT, SEBRAE/PI, ACEPOTI e } \\
\text { COOPERART }\end{array}$ \\
\hline 13 & Mostra Piauí Sampa & SEBRAE/PI \\
\hline 14 & Capacitação Profissional & $\begin{array}{l}\text { PMT, SEBRAE/PI, ACEPOTI e } \\
\text { COOPERART }\end{array}$ \\
\hline 15 & Incubadora de Artesanato Artístico de Teresina (INART) & SEMDEC, ACEPOTI e COOPERART \\
\hline 16 & Piauí Center Modas & SEMDEC, ACEPOTI e COOPERART \\
\hline 17 & Consultoria para a construção de fornos & SEBRAE/PI, ACEPOTI e COOPERART \\
\hline 18 & $\begin{array}{l}\text { Cursos profissionalizantes, orientações sobre o acesso ao } \\
\text { mercado, fortalecimento da cooperativa e promoção de ações } \\
\text { de melhoria na cadeia de produção }\end{array}$ & IW e COOPERART \\
\hline Fon: & Dados da pesquisa. & \\
\hline 12 & \\
\hline
\end{tabular}

Fonte: Dados da pesquisa.

Ressalta-se que as ações coletivas desenvolvidas foram relevantes para que o polo alcançasse o estágio em que se encontra, atuando como um APL formal e organizado. Percebeu-se que algumas ações específicas serviram de base para o surgimento de novas iniciativas, a exemplo do curso de associativismo que resultou na criação da Associação dos Artesãos em Cerâmica do Poti Velho (ACEPOTI). Além disso, ficou evidenciado também que a grande maioria das ações mapeadas tem como principais agentes a ACEPOTI (A19), a COOPERART (A30) e o SEBRAE/PI, demonstrando que tais agentes são extremamente importantes para o APL.

Com base nas iniciativas mapeadas, foi identificado que essas ações coletivas possuem duas propriedades relevantes: a de associativismo e a de qualificação, sendo que tais propriedades se revelam como importantes fontes de aprendizagem para o APL. Na Figura 1, a seguir, são apresentadas essas e outras propriedades identificadas nas ações coletivas do APL. 
Figura 1 - Ações coletivas, suas propriedades e associações

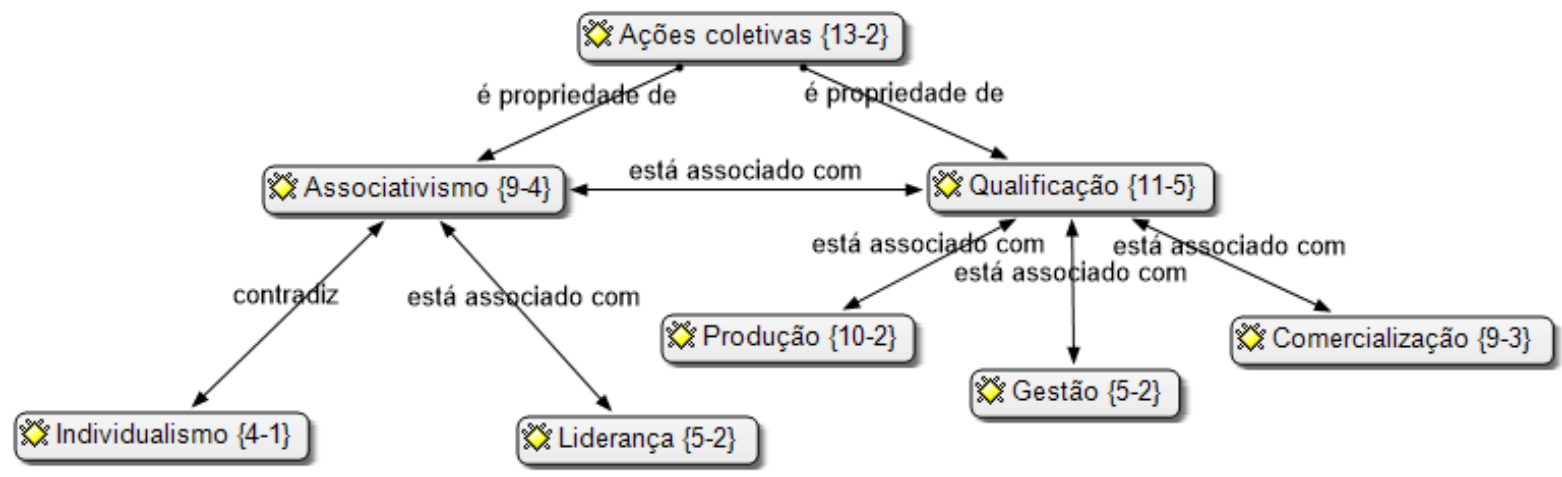

Fonte: Dados da pesquisa.

Inicialmente, cabe destacar que o individualismo foi considerado um ponto negativo para o grupo e que precisava ser superado. Com o trabalho individual, os artesãos só produziam potes, jarros e filtros, de baixa qualidade, inviabilizando a expansão comercial (Entrevistado A). Ainda, segundo o Entrevistado A, o individualismo foi também responsável pela falta de apoio de outros atores e de reconhecimento da profissão. Assim, o individualismo representou um entrave ao desenvolvimento do APL, necessitando, portanto, de iniciativas e práticas conjuntas.

Dentro dessa perspectiva, o curso de associativismo promovido pelo SEBRAE/PI com a adesão dos artesãos tornou-se a primeira ação coletiva que contribuiu para a consolidação do Arranjo Produtivo Local Arte Cerâmica Vermelha de Teresina. A promoção de tal ação vai ao encontro da percepção de que o fomento do associativismo é uma condição basilar para a emancipação e desenvolvimento de qualquer comunidade, articulando pontos específicos com os abrangentes. Desse modo, com esse despertar associativista, teve início a criação da Associação dos Artesãos em Cerâmica do Poti Velho (ACEPOTI), com a formação de lideranças, e a promoção de capacitação para os artesãos, por meio de diversos treinamentos e cursos. Conforme fala de um dos entrevistados:

Tudo começou com reunião na Boa Esperança com os oleiros e os artesãos. Foi um curso de associativismo com uma professora do SEBRAE. Aí surgiu a ACEPOTI. $E$, também, começou a vir treinamento, treinamento, e todos que vinha (sic) eu participava. Hoje eu tenho pra mais de 30 certificados nessa área. (Entrevistado C).

As ações associativas, além de estarem associadas à capacitação da rede, foram igualmente relevantes para que os artesãos aprendessem a importância da formação de lideranças, bem como a capacidade de identificá-las. "Eu considero que o crescimento veio assim que eles se apropriaram do conhecimento associativo e da identificação das lideranças. Isso foi fundamental para que eles reconhecessem que juntos eles poderiam realizar muitas coisas" (Entrevistado D). Assim, essa prática em formar lideranças foi adquirida, sobretudo, por meio de capacitação de um agente externo cooperando com atores internos, constituindo-se na forma de aprendizagem por cooperação (learning-by-cooperating), conforme Bureth, Wolff e Zanfei (1997). 
Esses líderes coletivos passam a coordenar a rede, buscando sempre obter ganhos e vantagens competitivas no mercado. Além disso, tais empreendedores, que são denominados de coletivos ou políticos, identificam ganhos privados em ações coletivas, como aponta a transcrição abaixo.

A ideia de formação da COPERART nasceu num curso que a gente fez. Daí eu conversei com as colegas e daí foi que nasceu essa ideia da gente pegar e formar a associação. Agente foi participando, participando dos outros curso. Comecei a participar das feira (sic) e daí eu vi que estava dando (sic) certo. Que agente tinha uma profissão, que além de ganhar um pouquinho mais que a olaria, tava (sic) me realizando profissionalmente, entendeu? (Entrevistado A).

Assim, observa-se que uma das formas de obtenção desses ganhos e vantagens competitivas para a rede adveio das ações coletivas que promoveram uma maior qualificação do arranjo. Além disso, verificouse que essa qualificação, além de ser uma propriedade das ações coletivas do arranjo, é uma genuína fonte de aprendizagem, estando associada às práticas de produção, de gestão e de comercialização.

No que se refere à produção, o Projeto Casa Piauí e a consultoria para a construção de fornos foram duas ações fundamentais ao aprimoramento das práticas artesanais. O Projeto Casa Piauí Design foi uma iniciativa do SEBRAE/PI com o apoio da ACEPOTI e da COOPERART, cujo objetivo buscou desenvolver produtos inovadores e de qualidade, que gerassem impacto no mercado, alinhando a produção artesanal ao design. Para tanto, o projeto contou com a colaboração de designers, monitores e arquitetos especialistas neste tipo de produção.

As peças mudaram muito, porque é aquele negócio: uma coisa é ter a prática, a outra é vir as pessoas com teoria. O SEBRAE começou com um projeto Casa Piauí Design, aonde tinha uma integração entre o artesão e o arquiteto (Entrevistado C). O mais bacana desse projeto é o equilíbrio entre as duas partes. O desenho arrojado de um designer e os saberes de um artesão. Ele hoje tem um produto de alto valor agregado. E esse produto encontrou um mercado e a agente se responsabiliza muito em conduzir essa produção. Todos nós ganhamos, todos nós podemos nos apresentar vibrando com essa conquista, com esses diferenciais que o Poti Velho estabelece frente ao mundo. (Entrevistado D).

É importante destacar que a colaboração entre os artesãos e os consultores especializados, em situação de trabalho, foi extremamente importante para a geração de novas práticas de trabalho, como enfatizam os entrevistados C e D. Foi constatado também, que tais práticas surgiram de encontros e conversas informais e espontâneas cuja finalidade era a resolução e o aprimoramento dos sistemas produtivos. Deste modo, o ambiente de trabalho constitui-se em uma fonte efetiva para o aprendizado organizacional, como destacam Ipiranga, Moreira e Amorim (2008). 
Igualmente, a consultoria para a construção de fornos foi outra iniciativa do SEBRAE/PI em parceria com a ACEPOTI e da COOPERART, visando a melhoria da qualidade do processo produtivo dos artesãos. Com a consultoria, os artesãos aprenderam utilizar o forno a gás, permitindo o controle maior sobre a temperatura e diminuindo o tempo de queima das peças. Aprenderam, também, a fazer modificações nos fornos à lenha e a construir formas para melhoria da queima e para criação de novos produtos.

Esse foi um momento muito importante para nós artesãos do polo. Agente aprendeu a usar forno gás e melhorar nossos fornos a lenha. Com essa consultoria, os nossos produtos melhorou (sic) muito em termo de qualidade e teve, também, maior valor no mercado. (Entrevistado G).

Outras ações coletivas como o curso de produção de bijuteria em cerâmica, curso de especialização em cerâmica e a capacitação em gestão e em design foram também relevantes para o aprimoramento do sistema produtivo do arranjo. Os resultados dessas capacitações, além da melhoria da qualidade, foram a diversificação e a inovação dos produtos comercializados, o que gerou, inclusive, uma demanda sazonal, como, por exemplo, a procura pelos presépios, que são produtos oriundos da arte santeira, comercializados nos meses de novembro e dezembro.

A gente trabalha com a linha decorativa. A linha decorativa é aquelas peças de todos os tamanhos: grande e pequena, que um produto de maior aceitação. Trabalhamos com a questão da linha utilitária, que vem mais as panela, os jarro e o filtro (sic). Trabalhamos com a parte de jardim, que são aquelas coisa bem coloridas pro jardim. A arte santeira também, que, por exemplo agora no final do ano, é aceitação maior, que são os presepi (sic) natalino. Trabalhamos também com a questão das bijuterias em cerâmica, que também foi outra novidade. Quando a gente lançou, nos foi que saiu na frente, com a bijuteria cerâmica toda natural. (Entrevistado A).

Dessa forma, percebeu-se uma grande influência dos atores externos atuando como fontes de informação para aprendizagem do arranjo. Ficou evidente, também, que a principal forma de aprendizagem, no que se refere às práticas de produção, é por meio da colaboração (learning-by-cooperating) entre os artesãos e outros atores (BURETH; WOLFF; ZANFEI, 1997), em especial aqueles de consultoria. 
Já no que diz respeito à gestão, as principais ações foram a formação da INART, com a atuação dos atores SEMDEC, ACEPOTI e COOPERART, a criação do Núcleo de Qualificação Profissional, cujos atores foram FWF, SENAI, SEBRAE/PI e CEFET, e a capacitação em gestão e em design, que foi promovida pelos agentes SEMDEC, SEBRAE/PI, ACEPOTI e COOPERART. No entanto, a ação que esteve mais em evidência na pesquisa, como fonte de novas práticas em gestão, foi o INART. O objetivo desse projeto foi promover a criação e o fortalecimento de empreendimentos na área do artesanato artístico atuando em APLs, uma vez que foi diagnosticado que tais negócios necessitavam de apoio tecnológico e capacitação empresarial para a inserção no mercado de forma competitiva.

A INART nos ajudou muito, tínhamos habilidade com o artesanato, mas percebemos que criar e administrar um negócio é outra coisa. Pelo INART, nós fizemos curso como, por exemplo, os cursos de plano de negócios, de gestão e de marketing (Entrevistado F).

As instituições tutoras das empresas incubadas, como as universidades, empresas de consultoria, entre outras, possuem grande repositório de conhecimento científico e tecnológico e de recursos humanos qualificados, que, comprometidamente, transferem esse acervo as empresas. As empresas incubadas têm a sua disposição uma gama de serviços especializados, usados de forma compartilhada, que são articulados para auxiliá-los na superação de barreiras técnicas e gerenciais, interpostas cotidianamente no caminho das empresas. Nesse sentindo, observou-se que o compromisso da instituição tutora em ensinar e o compromisso das empresas incubadas em aprender representam o elo dessas organizações que atuam de forma cooperada. É fato que as empresas possuem uma tendência a utilizar o compromisso para reduzir suas incertezas e estabelecer um ambiente mais estável para que a as práticas de cooperação e o learning-bycooperating (BURETH; WOLFF; ZANFEI, 1997) ocorra.

Por outro lado, mesmo com todo o sucesso que o projeto INART pode ter alcançado, ele não é capaz de promover a transferência de conhecimento científico e tecnológico para todos os empreendimentos da rede de forma mais imediata, limitando-se, tão somente, àqueles que foram selecionados. Além disso, pela pouca expressividade das outras ações coletivas voltadas à qualificação em gestão, alude-se que os treinamentos e os aperfeiçoamentos nesta área são insuficientes, o que pode comprometer o desempenho do arranjo.

No tocante à comercialização, as principais ações coletivas estão voltadas para a qualificação dos artesãos para participação em feiras, como a Semana de Moda de Teresina, a I Feira de Artesanato do Polo Cerâmico Artesanal do Poti Velho, a Mostra Piauí Sampa e o Piauí Center Modas. As feiras, neste caso, são consideradas como fonte de aprendizagem porque existe, nos momentos que antecedem os eventos, a preparação dos artesãos para produzirem inovações e produtos de qualidade.

Agente sempre aprende com as feiras. Para o Piauí Sampa, por exemplo, agente aprendeu a técnica de utilização da renda em peças de cerâmica. Foi um curso para os artesãos da COOPERART e da ACEPOTI. E no Piauí Sampa nosso trabalho ficou conhecido e valorizado, mais do que já é (Entrevistado F). 
Ademais, nesse processo de comercialização, a interação com clientes especializados representa uma importante fonte de informação. Ao atenderem as exigências de clientes criteriosos, os artesãos acabam inovando e criando novos produtos.

Eu estou satisfeito com o que ganho, seja por meio da comercialização aqui, no Poti Velho, seja expondo as peças em feiras no Piauí e em outros Estados, ou atendendo a clientes criteriosos e exigentes que encomendam peças de grande complexidade para decoração. Geralmente com o contato com esses clientes, agente está sempre produzindo coisa nova (Entrevistado F).

Dessa forma, a relação entre artesãos e consultores nas práticas de cooperação para aprendizagem de novas técnicas, como a utilização de rendas em peças de cerâmica, e nas práticas de interação dos artesãos com clientes especializados foram as principais formas de aprendizagem, learning-by-cooperating (BURETH; WOLFF; ZANFEI, 1997) e learning-by-interacting (LUNDVALL, 1998), identificadas no processo de comercialização. Com base em Malerba (1992), cabe destacar que esse processo apresentou uma maior diversificação nas formas de aprendizagem na relação com os atores externos do que os demais, faltando tão somente o aprendizado por imitação (learning-by-imitating). A Figura 2, a seguir, apresenta essas formas de aprendizagem e suas ações coletivas.

Figura 2 - Ações coletivas, suas propriedades, associações e formas de aprendizagem

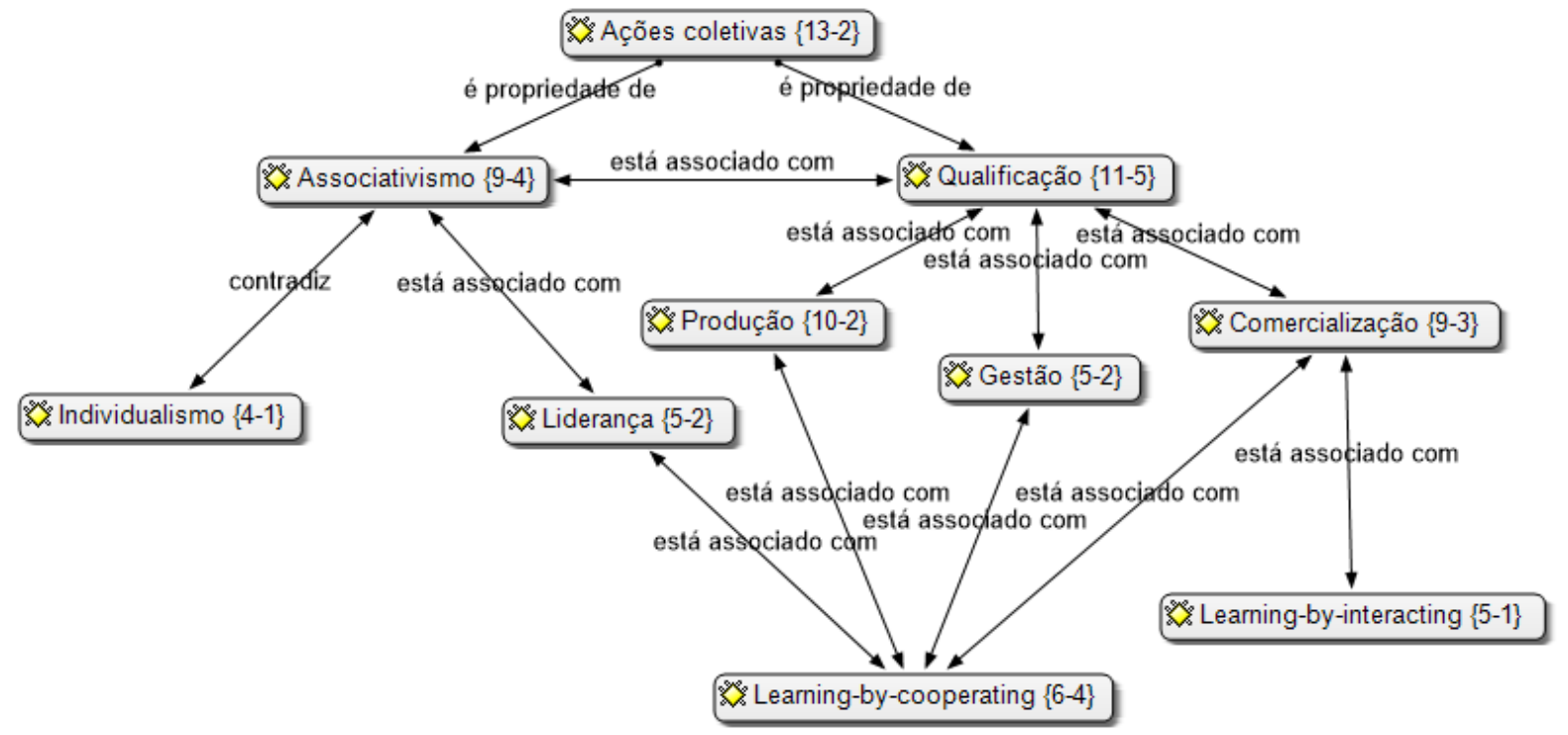

Fonte: Dados da pesquisa.

Em síntese, com base nos dados aqui apresentados, observou-se que as ações coletivas mapeadas são detentoras de duas qualidades importantes. A primeira possui o caráter de associativismo, que está relacionada, além da qualificação, com a formação de lideranças, por meio, especialmente, da aprendizagem por cooperação. A segunda tem um caráter de qualificação, estando associada às práticas de produção, de gestão e de comercialização, todas pelo meio da aprendizagem por cooperação, sendo que a prática de comercialização apresentou também como forma de aprendizagem a interação. Dessa forma, pode-se 
afirmas ques essas aprendizagens de cooperação (BURETH; WOLFF; ZANFEI, 1997) e de interação (LUNDVALL, 1988) ocorreram por meio da aprendizagem sócio-prática (IPIRANGA; MOREIRA; AMORIM, 2008), considerando as práticas de cooperação e de interação.

\section{CONSIDERAÇÕES FINAIS}

Tendo como objetivo geral analisar as principais ações coletivas existentes em um APL, identificando as suas influências na aprendizagem de seus agentes, este estudo buscou analisar as ações coletivas do APL Arte Cerâmica Vermelha de Teresina, no Piauí, descrevendo as influências dessas ações em sua aprendizagem. Inicialmente, foi possível identificar dois agentes internos, A30 e A19, e um agente externo, o SEBRAE/PI, apontados como os mais importantes para o APL, possuindo considerável prestígio e liderança no grupo, o que lhes confere certo poder. Esses indivíduos têm a função de conseguir informações e recursos necessários ao desenvolvimento das atividades, compartilhar habilidades e conhecimento, estabelecer alianças estratégicas e criar conexões indiretas.

Em relação às ações coletivas mapeadas, algumas se mostraram tão relevantes para o APL que serviram de base para o surgimento de novas ações. O somatório desses esforços conjuntos tornou possível o alcance de objetivos coletivos, mesmo que esta perspectiva de atingimento de objetivo não seja conscientemente vislumbrada, sobretudo, por seus atores internos, em sua totalidade. Ao mesmo tempo, pode-se afirmar que a maioria das ações coletivas mapeadas no APL estudado foi promovida a partir dos três agentes destacados. Esses agentes foram elementos relevantes que, por meio dos papeis acima descritos, proveram as principais ações para o grupo.

Ademais, verificou-se que as ações coletivas mapeadas no arranjo produtivo têm o caráter de associativismo e de qualificações. Por sua vez, essas qualidades especiais estão associadas às práticas de liderança, bem como aquelas práticas geradas das capacitações para o desenvolvimento e aprimoramento dos seus sistemas de produção, de gestão e de comercialização, constituindo-se em fontes de aprendizagem para o APL. Nesse sentido, constatou-se que a influência das ações coletivas na aprendizagem do arranjo estudado se dá por meio das práticas oriundas das ações associativas e de qualificações, uma vez que tais práticas (lideranças, produção, gestão e comercialização) são os processos nos quais as formas de aprendizagem pela cooperação e interação entre os agentes acontecem. Com isso, foi possível concluir que essas aprendizagens por cooperação e por interação aconteceram por intermédio da aprendizagem sócioprática, levando-se em consideração as práticas de cooperação e de interação presentes no arranjo.

Em termos de implicações práticas para o APL estudado, denota-se a relevância de tais resultados no sentido de ser possível a valorização e maior desenvolvido das práticas de aprendizagem coletiva aqui destacadas. De fato, os resultados apresentados, tanto em termos de descrição dessas práticas, assim como do papel mais atuante de alguns agentes locais neste processo, como o SEBRAE/PI, apontam caminhos para

o desenvolvimento e evolução das práticas de gestão, produção e comercialização por parte dos artesãos.

Ademais, alguns aspectos limitantes da pesquisa devem ser destacados. De início, a dificuldade do acesso aos sujeitos, principalmente na fase inicial da pesquisa, de mapeamento dos agentes do APL, demandou um esforço extra de visitas constantes ao APL durante um período maior do que o esperado a priori. No entanto, este contato diário, com os artesãos, familiares e empregados, durante as primeiras 
semanas de aplicação do questionário estruturado possibilitou uma familiaridade e reconhecimento por parte dos sujeitos da pesquisa, o que facilitou e deu abertura para a realização das entrevistas em profundidade, durante a etapa final da coleta de dados. Além disso, o não contato direto com os agentes externos identificados na pesquisa delimitou o conteúdo das análises às percepções apenas dos agentes internos do APL.

Por fim, como recomendação a estudos futuros, recomenda-se que esta pesquisa seja replicada em outras realidades, a fim de que sejam mapeadas todas as formas possíveis de aprendizagem decorrentes de ações coletivas, originadas pelo relacionamento dos seus agentes. Além disso, a replicação deste estudo em outras aglomerações produtivas será determinante para a verificação da sua fidedignidade e confiabilidade como modelo de pesquisa, bem como para confirmar ou não as teorias em que se fundamenta.

\section{REFERÊNCIAS}

ALVES-MAZZOTTI, A. Usos e abusos dos estudos de caso. Cadernos de Pesquisa, v. 36, n. 129, p. 637-651, set./dez. 2006.

ARGYRIS, C.; SCHON, D. Organizational learning: a theory of action perspective. Workingham: Addison-Wesley, 1978. ARROW, K. The economic implications of learning by doing. Review of Economic Studies, n.29, p.155-173. 1962.

BANDURA, A. Social learning through imitation. In: JONES, M. Nebraska Symposium on Motivation. Lincoln: University of Nebraska Press, 1962.

BRASIL. Ministério do Desenvolvimento, Indústria e Comércio Exterior. Grupo de Trabalho Permanente para Arranjos Produtivos Locais. Levantamento institucional. Brasil: MIDIC, 2008. Disponível em: http://www.mdic.gov.br/arquivos/dwnl_1210773301.pdf. Acesso em: 18 abr. 2011.

BURETH, A.; WOLFF, S.; ZANFEI, A. The two faces of learning by cooperating: the evolution and stability of inter-firm agreements in the European Electronics Industry. Journal of Economic Behaviour and Organisation, v. 32, p. 519-537, 1997.

BURRESS, M.; COOK, M. A primer on collective entrepreneurship: a preliminary taxonomy. Working paper AEWP 20091: University of Missouri, Department of Agricultural Economics, 2009.

CAMPOS, R. et al. Aprendizagem por interação: pequenas empresas em arranjos produtivos e inovativos locais. In: LASTRES, H.; CASSIOLATO, J.; MACIEL, M. (Orgs.). Pequena empresa: cooperação e desenvolvimento local. Rio de Janeiro: Relume Dumará, 2003, p. 51-65.

CASSIOLATO, J. Interação, aprendizado e cooperação tecnológica. Serie Contribuciones - Red Iberoamericana de Indicadores de Ciencia y Tecnologia. RICYT, 2004.

GODOY, A. Pesquisa qualitativa - Tipos Fundamentais. Revista de Administração de Empresas, São Paulo, v. 35, n. 3 , p. 20-29, maio/jun. 1995.

IPIRANGA, A. S. R.; MOREIRA, M. V. C.; AMORIM, M. A. A Comunidade de Prática da Rede NÓs: colaborando e compartilhando conhecimentos em arranjos produtivos locais. Organizações \& Sociedade, v. 15, p. 149-170, 2008.

JOHANNISSON, B. Entrepreneurship as a collective phenomenon. In: RENT XII, Lyon, França, nov. 1998.

LASTRES, H. et al. Interagir para competir: promoção de arranjos produtivos e inovativos no Brasil. Brasília: SEBRAE; FINEP; CNPq, 2002.

LASTRES, H.; CASSIOLATO, J. Glossário de arranjos e sistemas produtivos e inovativos locais. SEBRAE, 2003. Disponivel em: http://www.ie.ufrj.br/redesist. Acesso em: 15 out. 2011.

LIMA, A. M. Saúde e segurança do trabalhado do barro em arranjos produtivos: o caso do artesanato de barro nos bairros Olaria e Poti Velho. 2011. Tese (Doutorado em Geografia) - Universidade Estadual Paulista, Programa de Pós-Graduação em Geografia, Rio Claro, 2011.

LUNDVALL, B. Innovation as an interactive process: from user-production interaction to national system of innovation. In: DOSI, G. et al. Technical change and economic theory. London: Pinter, 1988.

MACIEL, M.; ALBAGLI, S. Conhecimento e aprendizado por interação: notas metodológicas para estudos empíricos em APLs. Rio de Janeiro: Redesist, 2002.

MALERBA, F. Learning by firms and incremental technical change. The Economic Journal, v.102, n. 413, jul. 1992. 
MATOS, F. R. N. O tecido empreendedor e o capital social costurando o desenvolvimento local: um estudo em um aglomerado de confecção no agreste pernambucano. 2008. Tese (Doutorado em Administração) - Universidade Federal de Pernambuco, Programa de Pós-Graduação em Administração (PROPAD), Recife, 2008.

MERRIAM, A. Qualitative research and study applications in education. São Francisco: Jossey-Bass, 1998.

MINAYO, M. O Desafio do conhecimento: pesquisa qualitativa em saúde. São Paulo: Hucitec, 2007.

MONTEIRO, M.; REGIS, H.; MELO, P. Redes sociais: o caso dos confeccionistas do apl de Santa Cruz do CapibaribePe. Revista de Negócios, Blumenau, v. 15, n.4, p. 49-65, out./dez.2010.

MORGAN, G. Imagens da organização. São Paulo: Atlas, 1996.

MUKOYAMA, T. Rosenberg's "learning by using" and technology diffusion. Journal of Economic Behavior \& Organization, Elsevier, v. 61, n. 1, p. 123-144, Sep. 2006.

PETERS, J. Um programa de estudos. HSM Management, v. 9, p. 74-80, jul./ago. 1998.

PIAUÍ. Fundação Centro de Pesquisas Econômicas e Sociais do Piauí. Diagnóstico e diretrizes para o setor mineral do estado do Piauí. Teresina, 2005.

ROSENBERG, N. Inside de black box: technology and economics, Cambridge University Press, 1982.

SENGE, P. A Quinta disciplina. São Paulo: Best Seller, 1990.

SERVIÇO BRASILEIRO DE APOIO ÀS MICRO E PEQUENAS EMPRESAS. Boletim Estatístico de Micro e Pequenas $\begin{array}{llll}\text { Empresas. } & \text { Brasilia: } & \text { SEBRAE, } & \text { Disponível }\end{array}$ http://www.sebraemg.com.br/arquivos/parasuaempresa/boletimestatisticompe/boletim_estatistico_mpe.pdf. Acesso em: 29 fev. 2011.

SILVA, T. O Homem sua arte seu lugar - promoção de empreendimentos orientados para o desenvolvimento local e setorial. In: Rede de Tecnologia \& Inovação do Rio de Janeiro. Disponível em: http://www.redetec.org.br/publique/media/x\%20Teresinha\%20de\%20Jesus \%20Ferreira\%20da\%20Silva.pdf. Acesso em: 21 jun. 2011.

SILVERMAN, D. Interpretações de dados qualitativos: métodos para análise de entrevistas, texto e interações. 3. ed. Porto Alegre: Artmed, 2009.

TERESINA. Teresina em bairros. Teresina: Secretaria Municipal de Planejamento e Coordenação Geral, 2003.

VERGARA, S. Métodos de pesquisa em administração. 4. ed. São Paulo: Atlas, 2010.

YIN, R. Estudo de caso: planejamento e métodos. 3.ed. Porto Alegre: Bookman, 2005. 